\title{
Analisa fatigue life konstruksi geladak pada kapal Landing Craft Tank menggunakan metode elemen hingga
}

\author{
Alamsyah $^{1^{\star}}$, Merlistyo Driantama Arwan², Amalia Ika Wulandari ${ }^{3}$ \\ 1,2,3Teknik Perkapalan, Institut Teknologi Kalimantan \\ JI. Soekarno Hatta No.KM 15, Karang Joang, Kec. Balikpapan Utara, Kota Balikpapan, \\ Kalimantan Timur 76127, Indonesia \\ *Corresponding author: alamsyah@lecturer.itk.ac.id
}

\begin{abstract}
The Landing Craft Tank ship is the usual vessels used to transport massive vehicles like excavator, bulldozer, heavy cargo and other heavy equipment indispensable for construction work. There are heavy equipment decks on the LCT vessels that are use to hold or support the cargo above it. The purpose of this study was to determine the stress value in the deck construction that has been modeled before with a plate thickness variation of $80 \%, 90 \%$ and $100 \%$ which is then followed by finding the value of fatigue life in the deck construction. The method used in the analysis this time is the finite element method which models the construction deck of LCT vessels assisted by finite element based applications. From the results of the study it was found that the stress on the deck construction of LCT vessels with plate thickness $100 \%$ was $99.513 \mathrm{MPa}$, plate thickness $90 \%$ was $104.72 \mathrm{MPa}$ and at plate thickness $80 \%$ was 105.19 MPa. While the value of fatigue life with a deck plate thickness of $100 \%$ is 26.84 years with a number of cycles of 1006700 times, deck plate thickness of $90 \%$ is 16.22 years with a number of cycles 129000 times and deck plate thickness of $80 \%$ is 15.91 years with a number of cycles 125000.
\end{abstract}

Keywords: Landing Craft Tank, finite element, fatigue life.

\begin{abstract}
Abstrak
Kapal Landing Craft Tank (LCT) merupakan kapal yang biasanya digunakan untuk mengangkut kendaraan-kendaraan besar seperti excavator, bulldozer, heavy cargo, dan alat berat lainnya yang sangat diperlukan untuk pekerjaan konstruksi. Terdapat deck kendaraan alat berat pada kapal LCT yang yang difungsikan untuk menahan atau menopang muatan yang ada di atasnya. Tujuan penelitian ini untuk mengetahui nilai tegangan pada konstruksi geladak yang telah dimodelkan sebelumnya dengan variasi ketebalan plat sebesar $80 \%, 90 \%$, dan $100 \%$ yang kemudian dilanjutkan dengan mencari nilai fatigue life pada konstruksi geladak tersebut. Metode yang digunakan pada analisa kali ini adalah metode elemen hingga yang memodelkan konstruksi geladak kapal LCT dibantu aplikasi berbasis elemen hingga. Dari hasil penelitian didapatkan tegangan pada konstruksi geladak LCT dengan ketebalan pelat $100 \%$ sebesar 99.513 Mpa, ketebalan pelat $90 \%$ sebesar 104.72 Mpa dan pada ketebalan pelat $80 \%$ sebesar 105.19 Mpa. Sedangkan nilai fatigue life dengan ketebalan pelat geladak $100 \%$ yakni 26.84 tahun dengan jumlah siklus 1006700 kali, ketebalan pelat geladak 90\% yakni 16.22 tahun dengan jumlah siklus 129000 kali dan ketebalan pelat geladak 80\% yakni 15.91 tahun dengan jumlah siklus 125000 .
\end{abstract}

Kata kunci: Landing Craft Tank, elemen hingga, umur kelelahan.

\section{Pendahuluan}

Landing Craft Tank (LCT) adalah salah satu jenis kapal dari beberapa macam jenis kapal yang ada. Kapal ini awalnya merupakan kapal serbu amfibi untuk pendaratan tank di pantai. Kapal LCT memiliki ramp door, ruang geladak terbuka, dan sarat yang rendah. Terbukanya ruang geladak memungkinkan LCT untuk 
membawa berbagai jenis kargo yang berat dan besar. Sedangkan draft yang rendah memungkinkan LCT untuk berlayar melewati perairan yang dangkal. Selain mengangkut kargo, LCT juga dapat mengangkut alat-alat berat dari pulau ke pulau lainnya [1].

Sesuai dengan namanya kapal ini terdiri dari tanki-tanki void pada daerah di bawah geladak utama sedangkan muatannya terletak pada bagian atas geladak utama. Secara umum kapal ini mirip dengan ponton namun memiliki mesin penggerak dan ruang-ruang akomodasi, pada bagian depan terdapat bagian pintu rampa (ramp door) untuk akses masuk muatan. Karena kapal ini seperti ponton maka kecepatannya juga relatif lambat jika dibandingkan dengan kapal kontainer pada umumnya yaitu sekitar 8,5 knot [2].

Proses perancangan struktur geladak pada kapal LCT sangat perlu diperhatikan agar dapat memenuhi faktor keamanan konstruksi dimana bisa menjamin keselamatan kapal ketika beroperasi. Safety factor atau faktor keamanan adalah faktor yang menunjukkan tingkat kemampuan suatu bahan teknik dari beban luar, yaitu beban tekan maupun tarik. Untuk desain bagian-bagian struktur tingkat tegangan disebut tegangan ijin (alloweble stress) dibuat benar-benar lebih rendah dari pada kekuatan ultimate yang diperoleh dari pengujian "statis". Ini penting untuk berbagai pertimbangan. Besar gaya yang dapat bekerja pada bangunan/konstruksi yang dirancang jarang diketahui secara pasti [3].

Geladak LCT menerima beban besar berupa alat berat yang seiring berjalannya waktu akan megalami kelelahan karena adanya siklus beban yang berulang (beban siklik). Pada umumnya geladak yang berada di bawah sendiri dinamakan geladak dasar serta geladak yang di atas dinamakan geladak atas atau geladak utama (main deck). Bila antara geladak dasar dan geladak atas terdapat geladak lagi, maka geladak tersebut dinamakan geladak [4]. Pada penelitian ini dilakukan analisa kelelahan struktur dan faktor keamanan yang berfokus pada konstruksi geladak utama LCT dengan mengasumsikan bahwa konstruksi geladak utama kapal yang mengalami penipisan akibat lingkungan korosif.

\section{Metode Penelitian}

Penelitian ini menggunakan metode elemen hingga dengan bantuan aplikasi berbasis elemen hingga. Jenis data yang digunakan pada penelitian ini berupa data primer yang digunakan dalam proses pemodelan konstruksi geladak utama kapal LCT. Data ukuran utama kapal bersumber dari PT. XYZ yang ditunjukkan pada Tabel 1 sebagai berikut :

Tabel 1. Data Ukuran Utama Kapal LCT

\begin{tabular}{ccc}
\hline No. & Particular & $\begin{array}{c}\text { Ukuran } \\
\text { (meter) }\end{array}$ \\
\hline 1 & Length over All (LoA) & 38.15 \\
\hline 2 & $\begin{array}{c}\text { Length Between } \\
\text { Perpendicular (LBP) }\end{array}$ & 35.63 \\
\hline 3 & Breadth $(\mathrm{B})$ & 8 \\
\hline 4 & Height $(\mathrm{H})$ & 2.2 \\
\hline 5 & Draft $(\mathrm{T})$ & 1.5 \\
\hline
\end{tabular}

Selain data ukuran utama kapal digunakan juga data General Arragement yang ditunjukkan pada Gambar 1.

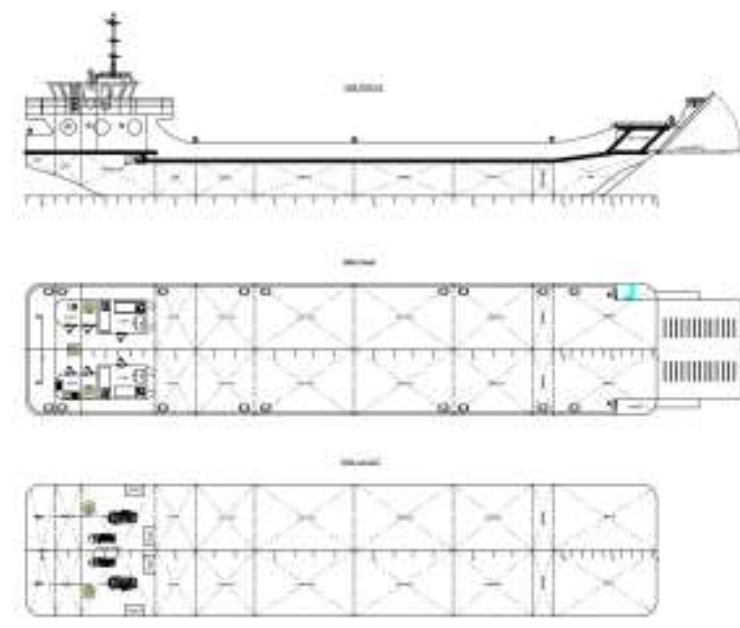

Gambar 1. GA Kapal LCT

Untuk kebutuhan pemodelan $3 D$ sampai pada detail konstruksi maka digunakan juga data konstruksi kapal yang ditunjukkan pada Gambar 2. 

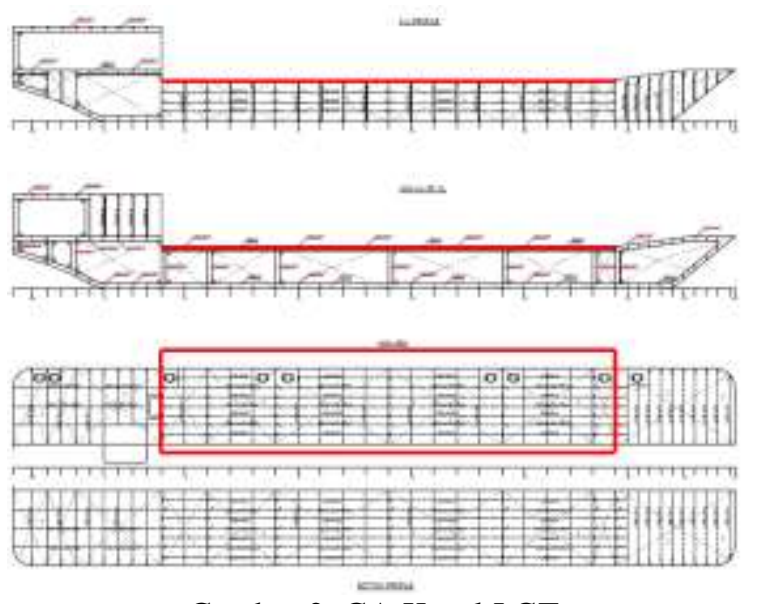

Gambar 2. GA Kapal LCT

Pada Gambar 2 menunjukkan garis marking merah yang merupakan detail konstruksi geladak utama kapal yang menjadi objek penelitian dimana konstruksi tersebut akan dimodelkan secara $3 D$ pada aplikasi berbasis elemen hingga. Metode elemen hingga (finite element) biasa dipandang sebagai perluasan dari metode perpindahan (untuk struktur rangka) ke masalah kontinum berdimensi dua dan tiga seperti pelat, struktur selaput (shell) dan benda pejal. Dalam metode ini, kontinum sebenarnya diganti dengan sebuah struktur ideal ekivalen yang terdiri dari elemenelemen unik (discrete element). Elemen ini disebut elemen berhingga dan dihubungkan bersama-sama di sejumlah titik simpul [2]. Metode elemen hingga telah digunakan secara luas untuk menyelesaikan berbagai persoalan mekanika dengan geometri yang kompleks. Metode ini bisa digunakan untuk menganalisa kekuatan komponen-konponen konstruksi pada kapal mulai yang paling komplek sampai yang paling sederhana seperti misalnya pada bracket [5]. Detail konstruksi pada objek penelitian ditunjukkan pada Tabel 2 .

Tabel 2. Detail Konstruksi yang dimodelkan

\begin{tabular}{ccc}
\hline No. & Konstruksi & Ukuran $(\mathrm{mm})$ \\
\hline 1 & Panjang Geladak & 24000 \\
\hline 2 & Lebar Geladak & 8000 \\
\hline 3 & Long. Deck Girder & $250 \times 12+100 \times 12 \mathrm{Flg}$ \\
\hline 4 & Long. Deck Frame & L80x80x8 \\
\hline 5 & Tans. Deck Beam & L250x70x7 \\
\hline 6 & Deck Plate Thick. & 8 \\
\hline
\end{tabular}

Dalam pemodelan ini menggunakan sumbu $x, y$ dan $z$ atau biasa disebut dengan $3 D$ modeling. Dimana dalam hal ini, sumbu $x$ mewakili lebar dari desain model, sumbu $y$ mewakili panjang dari desain model, dan sumbu $z$ mewakili ketebalan atau ketinggian dari desain model.

Langkah selanjutnya dilakukan perhitungan beban pada geladak utama kapal. Beban yang digunakan yakni beban aktual ketika kapal beroperasi untuk memberikan hasil analisa yang komprehensif dan sesuai yang terjadi di lapangan. Beban yang digunakan yakni 4 unit Excavator PC230LC-8 dengan total berat $82800 \mathrm{~kg}$. Sehingga nilai beban yang diinputkan pada model ditentukan menggunakan persamaan berikut [6].

$$
\text { Load }_{\text {press }}=\frac{\text { Total beban }}{\text { luas penampang model }}
$$

Langkah selanjutnya dilakukan perhitungan tegangan yang terjadi pada konstruksi geladak utama kapal LCT. Suatu tegangan pada sebuah titik, secara matematis dapat diketahui dengan menggunakan persamaan berikut [7]:

$$
\sigma=\frac{P}{A}
$$

Dimana $P$ adalah suatu gaya yang bekerja tegak lurus terhadap potongan, sedangkan $A$ merupakan luas yang bersangkutan. Selain itu tegangan normal dapat menghasilkan tegangan tarik (tensile stress), tegangan tekan (compressive stress) dan tegangan geser (shearing stress) [7]. Tegangan yang lebih umum digunakan pada model konstruksi $3 D$ adalah tegangan equivalent [8].

$$
\sigma_{v}=\sqrt{\sigma^{2}+3 \tau^{2}}
$$

$\sigma_{v}$ adalah tegangan equivalen, $\sigma$ adalah tegangan normal, dan $\tau$ adalah tegangan geser.

Nilai tegangan yang terjadi pada konstruksi geladak utama kapal disimulasikan dalam 3 kondisi dimana dilakukan variasi ketebalan pelat pada geladak utama. Konstruksi diasumsikan mengalami penipisan akibat lingkungan korosif yang dialami oleh kapal sehingga 
ketebalan pelat diasumsikan pada kondisi $100 \%$, 90\%, dan $80 \%$ dari ukuran yang sebenarnya.

Tahap selanjutnya menentukan nilai faktor keamanan (safety factor) konstruksi dengan membandingkan hasil tegangan kerja maksimum yang terjadi pada konstruksi dengan tegangan luluh material yang digunakan pada konstruksi. Untuk menghitung faktor keamanan digunakan persamaan berikut [9].

$$
F k=\frac{\sigma_{\text {yield }}}{\sigma_{\text {Kerja Maksimum }}}
$$

$\sigma_{\text {yield }}$ adalah tegangan luluh material, $\sigma_{\text {KerjaMaksimum }}$ adalah tegangan maksimum yang bekerja pada konstruksi, dan $F k$ adalah faktor keamanan $(F k>1)$ [9].

Pada tahap akhir menentukan nilai umur kelelahan (fatigue life) dengan regulasi klasifikasi kapal DNV rules. Untuk mengetahui umur kelelahan maka harus diketahui nilai fatigue damage terlebih dahulu dengan menggunakan simplified fatigue analysis yang bersumber dari DNVGLRP-0005:2014-06 [10]. Adapun nilai fatigue damage bisa ditentukan dengan menggunakan persamaan berikut [10][11]:

$$
\begin{aligned}
& D=\frac{v_{0} T_{d}}{\bar{a}} q^{m} r\left(1+\frac{m}{n}\right) \leq \eta \\
& v_{0}=\frac{1}{4 \cdot \log _{10}(L)} \\
& q=\frac{\Delta \sigma_{0}}{\left(\operatorname{In} n_{0}\right)^{1 / h}} \\
& h_{0}=2.21-0.54 \log _{10}(L) \\
& h=h_{0}+\frac{h_{a} \times z}{T_{a c t}}-0.005\left(T_{a c t}-z\right)
\end{aligned}
$$

$D$ adalah accumulated fatigue demmage, $v_{0}$ adalah average zero up-crossing frequency, $q$ adalah weibull stress range scale distribution parameter, $h$ adalah weibull stress range shape distribution parameter, $T_{d}$ adalah design service life of ship, $\mathrm{r}(1+\mathrm{m} / \mathrm{h})$ adalah gamma function, $\bar{a}$ adalah intercept of the design $S-N$ curve with the log $N$ axis, dan $\Delta \sigma_{0}$ adalah the largest stress range out of $n_{0}$ cycles.

Setelah fatigue damage diketahui lalu digunakan persamaan berikut untuk menentukan umur kelelahan struktur [10].

$$
\text { Fatigue Life }=\frac{\text { Design Life }}{D} \times \text { years }
$$

Fatigue life adalah umur kelelahan, design life digunakan 20 tahun sesuai aturan DNV, $D$ adalah fatigue damage, dan years adalah digunakan 1 tahun.

\section{Hasil dan Pembahasan}

Pemodelan konstruksi geladak utama kapal LCT menggunakan aplikasi berbasis elemen hingga ditunjukkan pada Gambar 3.

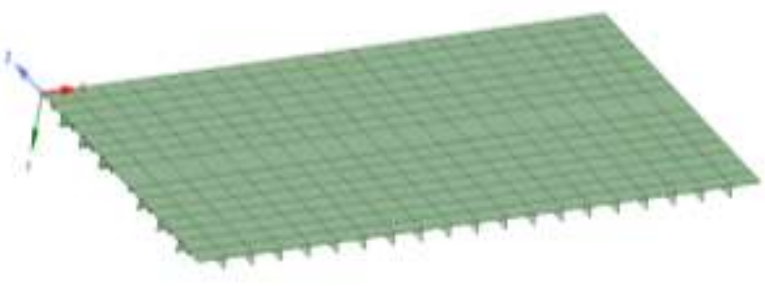

(a)

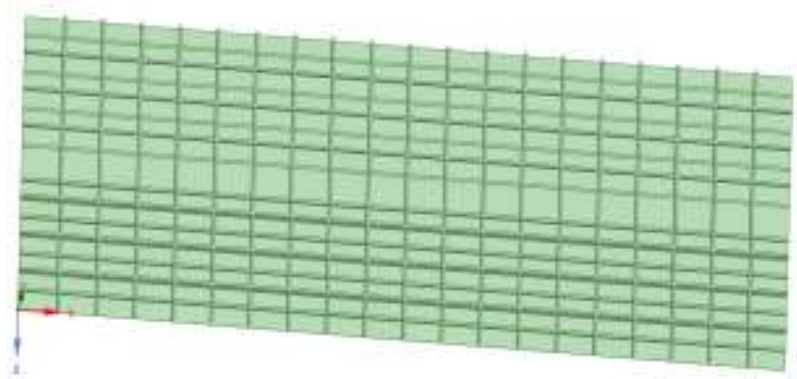

(b)

Gambar 3. a) tampak atas pemodelan 3D geladak utama kapal LCT, b) tampak bawah pemodelan 3D geladak utama kapal LCT

Setelah dilakukan pemodelan 3D maka salah satu tahapan wajib yang dilakukan pada model 3D konstruksi adalah proses meshing. Hal ini merupakan tahapan ketika menggunakan aplikasi berbasis elemen hingga. Meshing model ditunjukkan pada Gambar 4.

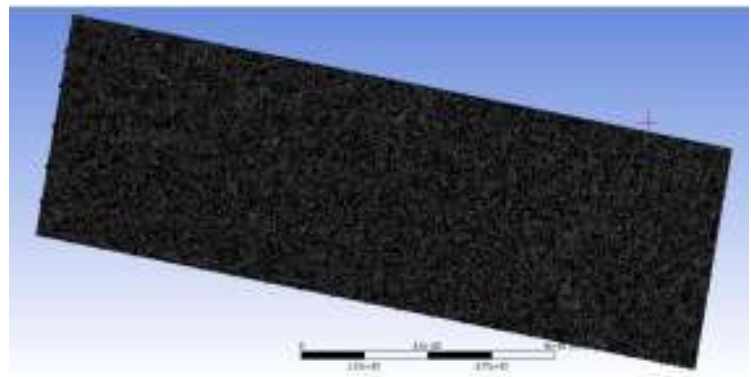

Gambar 4. Model 3d konstruksi geladak utama yang di-meshing.

Gambar 4 menunjukkan hasil meshing pada desain geladak utama dengan element 
size sebesar $50 \mathrm{~mm}$. Pada meshing didapatkan jumlah nodes dan elements pada desain model 426348 nodes dan 1291505 elements. Setelah proses mesh selesai, diberikan tumpuan dan beban pada model dengan memilih fixed support dan beban pressure yang ditunjukkan pada Gambar 5.

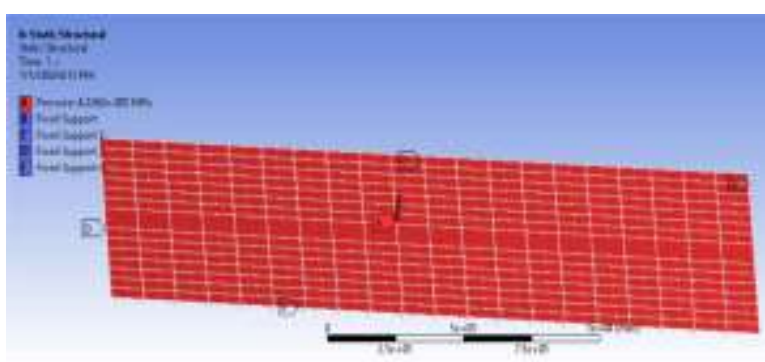

Gambar 5. Proses input tumpuan dan beban.

Gambar 5 menunjukkan bahwa masing-masing huruf pada gambar menunjukkan letak dan perannya. Huruf A merupakan letak beban sedangakan huruf B, $\mathrm{C}, \mathrm{D}$, dan $\mathrm{E}$ menunjukkan letak tumpuan jepit yang di input pada model 3D. Nilai beban pressure ditentukan dengan menggunakan persamaan 1 sehingga didapatkan beban yang diinput pada model sebesar $0.00422625 \mathrm{MPa}$.

Tahap selanjutnya yang dilakukan menggunakan aplikasi berbasis elemen hingga ini yakni perhitungan nilai tegangan. Nilai tegangan konstruksi diproleh setelah melakukan running model pada tahap analysis. Proses running model dilakukan pada setiap variasi ketebalan pelat pada geladak utama kapal, yakni ketebalan 6.4 $\mathrm{mm}$ (80\%), $7.2 \mathrm{~mm} \mathrm{(90 \% ),} \mathrm{dan} 8 \mathrm{~mm}$ $(100 \%)$. Adapun nilai tegangan yang diperoleh dari aplikasi berbasis elemen hingga ditunjukkan pada Gambar 6.

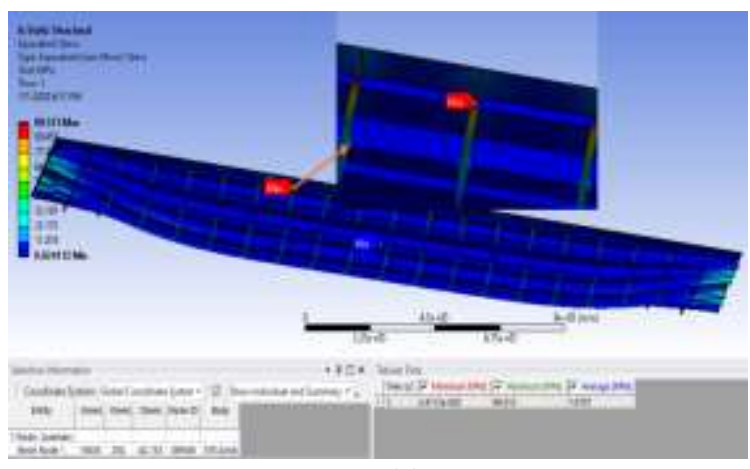

(a)

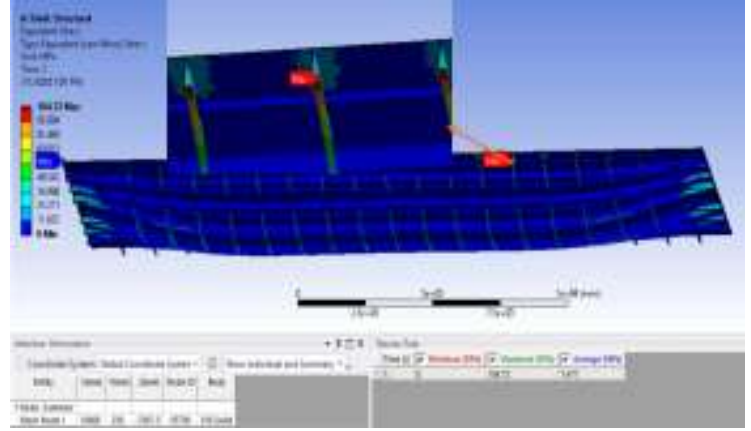

(b)

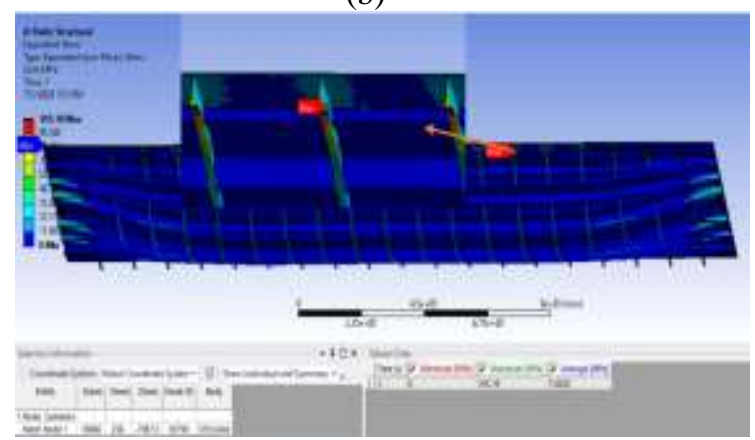

(c)

Gambar 6. a) Nilai tegangan dengan tebal pelat 8 $\mathrm{mm}$, b) Nilai tegangan dengan tebal pelat $7.2 \mathrm{~mm}$, dan c) Nilai tegangan dengan tebal pelat $6.4 \mathrm{~mm}$.

Rekapitulasi hasil running model 3D geladak utama kapal menggunakan aplikasi berbasis elemen hingga ditunjukkan pada Tabel 3.

Tabel 3. Rekapitulasi hasil running model geladak utama kapal.

\begin{tabular}{ccc}
\hline $\begin{array}{c}\text { Ketebalan } \\
\text { Pelat } \\
\begin{array}{c}\text { Geladak } \\
(\mathrm{mm})\end{array}\end{array}$ & $\begin{array}{c}\text { Tegangan arah } \\
\mathrm{x}(\mathrm{Mpa})\end{array}$ & $\begin{array}{c}\text { Letak } \\
\text { tegangan } \\
\text { (nomor } \\
\text { node) }\end{array}$ \\
\hline 8 & 99.51 & 389546 \\
\hline 7.2 & 104.72 & 65790 \\
\hline 6.4 & 105.19 & 65790 \\
\hline
\end{tabular}

Selanjutnya dilakukan perhitungan faktor keamanan konstruksi dengan menggunakan persamaan 3 sehingga didapatkan nilai faktor keamanan yang ditunjukkan pada Tabel 4.

Tabel 4. Faktor keamanan konstruksi.

\begin{tabular}{ccc}
\hline $\begin{array}{c}\text { Tegangan } \\
\text { luluh } \\
\text { (Mpa) }\end{array}$ & $\begin{array}{c}\text { Tegangan kerja } \\
\text { max. (Mpa) }\end{array}$ & Fk \\
\hline 210 & 99.51 & 2.11 \\
\hline 210 & 104.72 & 2 \\
\hline 210 & 105.19 & 1.9 \\
\hline
\end{tabular}


Tabel 4 menunjukkan nilai faktor keamanan pada konstruksi ketika terjadi tegangan kerja untuk semua kondisi ketebalan pelat yakni $\mathrm{Fk}>1$ sehingga dapat disimpulkan bahwa konstruksi geladak utama kapal LCT tersebut aman. Tahap akhir dari penelitian ini yakni menentukan umur kelelahan konstruksi dengan menggunakan persamaan 5, 6, 7, 8, 9, dan 7 . Nilai fatigue damage, fatigue life untuk masing-masing tegangan kerja maksimum ditunjukkan pada Tabel 5.

Tabel 5. Fatigue life konstruksi geladak utama kapal LCT

\begin{tabular}{cccl}
\hline $\begin{array}{c}\text { Ketebalan } \\
\text { pelat } \\
(\mathrm{mm})\end{array}$ & $\begin{array}{c}\text { Siklus } \\
\text { beban }\end{array}$ & $D$ & $\begin{array}{l}\text { Fatigue } \\
\text { Life } \\
\text { (tahun) }\end{array}$ \\
\hline 8 & 1006700 & 0.75 & 26.84 \\
\hline 7.2 & 129000 & 1.23 & 16.22 \\
\hline 6.4 & 125000 & 1.25 & 15.91 \\
\hline
\end{tabular}

Dari hasil analisis dengan tiga variasi ukuran ketebalan geladak utama kapal LCT maka didapatkan bentuk $S-N$ Curve yang ditunjukkan pada Gambar 7.

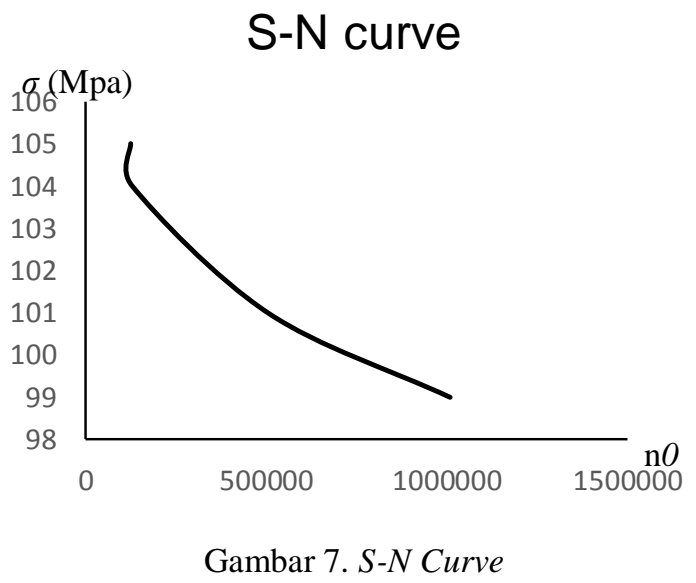

Gambar 7 menunjukkan nilai siklus sebesar 1006700 kali pada tegangan 99.513 Mpa, nilai siklus sebesar 129000 kali pada tegangan $104.72 \mathrm{MPa}$ dan nilai siklus sebesar 125000 kali pada tegangan 105.19 Mpa. Dari hasil ini dapat disimpulkan bahwa nilai siklus berbanding terbalik dengan nilai tegangan [12-14].

\section{Kesimpulan}

Konstruksi geladak utama kapal LCT dideteksi dalam kondisi aman dengan nilai $\mathrm{Fk}>1$. Nilai fatigue life pada konstruksi geladak utama kapal LCT yang telah dimodelkan pada aplikasi berbasis elemen hingga dengan variasi ketebalan pelat $8 \mathrm{~mm}$ (100\%) adalah 26.84 tahun dengan nilai fatigue damage sebesar 0.75 dan mempunyai siklus sebanyak 1006700 kali. Untuk ketebalan pelat $7.2 \mathrm{~mm} \mathrm{(90 \% )}$ memiliki fatigue life sebesar 16.22 tahun dengan nilai fatigue damage sebesar 1.23 dan mempunyai siklus sebanyak 129000 kali. Sedangkan ketebalan pelat $6.4 \mathrm{~mm}$ (80\%) memiliki fatigue life sebesar 15.91 tahun dengan nilai fatigue damage sebesar 1.25 dan mempunyai siklus sebanyak 125000 kali. Pada penelitian selanjutnya dapat dilakukan dengan variasi penambahan variabel loadcase agar mendapat hasil perbandingan.

\section{Ucapan terimakasih}

Ucapan terimakasih pada PT.XYZ karena telah memberikan data primer penelitian berupa GA dan gambar konstruksi kapal LCT. Terimakasih pula kepada laboratorium perencanaan desain konstruksi dan permesinan kapal program studi teknik perkapalan karena telah memfasilitasi penelitian ini. Terimakasih juga kepada reviewer yang tidak diketahui namanya yang telah memberikan masukan, saran yang membangun sehingga paper ini layak dipublikasikan.

\section{Referensi}

[1] F. F. Rosid, I. P. Mulyatno, dan S. E. Hadi (2017) "Analisa Kekuatan Konstruksi Kapal Landing Craft Tank Teluk Katurei Akibat Perubahan Framing System Dengan Metode Elemen Hingga," J. Tek. Perkapalan, 5(3), 502-508.

[2] K. A. Prasetyo, 2012 "Modifikasi Kapal LCT Pengangkut Alat Berat Adinda Azula Menjadi Kapal Container," Surabaya, [Online]. 
Available: http://digilib.its.ac.id/ITSpaper-42001120000657/20707.

[3] A. Mukhsin, I. P. Mulyatno, dan S. J. Sisworo (2016) "Analisa Kekuatan Konstruksi Car Deck Akibat Penambahan Deck Pada Ruang Muat Kapal Motor Zaisan Star 411 DWT Dengan Metode Elemen Hingga," J. Tek. Perkapalan, 4 (2), 341-351.

[4] A. A. Romani, I. P. Mulyatno, and G. Rindo, (2015) "Analisa Kekuatan Modifikasi Konstruksi Geladak Utama Kapal LCT Vip Jaya 893 GT Dengan Metode Elemen Hingga," $J$. Tek. Perkapalan, 3 (2), 300-308.

[5] Alamsyah, A. I. Wulandari dan B. Harseno. (2020) "Analisa Kekuatan Bracket Pada Kapal Ro-Ro Menggunakan Aplikasi Finite Element," SPECTA J. Technol., 4 (3), 97-105.

[6] M. D. Arwan, 2020 "Analisa Fatigue Life Konstruksi Deck Pada Kapal Landing Craft Tank (LCT) Wijaya 838 Dengan Metode Elemen Hingga," TA Program Studi Teknik Perkapalan, Institut Teknologi Kalimantan, Tidak dipublikasikan.

[7] R. C. Hibbeler, 2018, Mechanics of Materials in SI Units, 10th Edition. Pearson.

[8] BKI, 2017, Rules for the classification and Construction. Part 1 Seagoing Ship.Volume $V$ Rules for Materials. Jakarta: BKI.

[9] Alamsyah, A. I. Wulandari, dan N. R. Pamungkas. (2020) "Analisis Kekuatan Struktur Pondasi Mesin Kapal TB. Sungai Sepaku 155 GT Dengan Metode Elemen Hingga," TRAKSI Maj. Ilm. Tek. Mesin, 20 (1), 45-58.

[10] DNVGL, 2019, Fatigue Design of Offshore Steel Structure.

[11] I. Lotsberg, (2017) "Development Of Fatigue Design Standards For Marine Structures," in Proceedings of the ASME 2017 36th International Conference on Ocean, Offshore and Arctic Engineering, 1-12.
[12] Budiyanto, E., Nugroho, E., \& Zainudin, A. (2018). Uji ketahanan fatik aluminium scrap hasil remelting piston bekas menggunakan alat uji fatik tipe rotary bending. Turbo: Jurnal Program Studi Teknik Mesin, 7(1).

[13] Nugroho, E., Budiyanto, E., Kurniawan, R., \& Sumosusilo, J. (2020). Uji ketahanan fatik aluminium hasil remelting piston bekas menggunakan metode pengecoran centrifugal casting. Turbo: Jurnal Program Studi Teknik Mesin, 8(2).

[14] Wahyono, W., Nugroho, E., Handono, S. D., \& Budiyanto, E. (2020). Analisa uji ketahanan fatigue Aluminium scrap hasil remelting sepatu rem (brake shoe) terhadap variasi beban menggunakan tipe rotary bending. ARMATUR: Artikel Teknik Mesin \& Manufaktur, 1(2), 96-107. 